\title{
Optimized Profit Allocation in An Agricultural Supply Chain of Sichuan
}

\author{
Yuying Du \\ The Engineering \& Technical College of Chengdu University of Technology, \\ Leshan, Sichuan, China, 999078 \\ E-mail:512316180@qq.com
}

\begin{abstract}
Based on the Shapely Value, this paper analyzed the profit allocation among the cooperative enterprises in a supply chain, and tried to optimize it to apply specifically to an agricultural supply chain of Sichuan.
\end{abstract}

Keywords- Agricultural Supply Chain; Profit Allocation; Optimization

\section{INTRODUCTION}

The market competition has gradually shifted from enterprises to the supply chain. On one hand, the relationship of the cooperative enterprises in the supply chain is, in essence, a kind of trade. Thus, the cooperative enterprises in the supply chain, as independent economic entities, would compete not only for a better position and more profits in the supply chain but also for more interests in the allocation. On the other hand, these cooperative enterprises in the supply chain would competitively cooperate with each other, for they have to trust and coordinate with each other to meet the demands of customers quickly. As researchers is known to all, it is necessary for a modern company to give a quick response to the various demands of customers, so as to establish itself in the market and get a maintainable development. Thus, individual companies have to cooperate with other companies to grasp the opportunities in the market and form a supply chain to face the competitive market.

As the enterprises in the supply chain are independent economic entities and they would try their best to maximize the profits they can get, whether the profit allocation in the supply chain is reasonable would have a direct impact on the efficiency and stability of the sully chain. However, the cooperative enterprises in the supply chain are just strategic partners who rely on the integration and optimum utilization of resources to respond quickly to the market and save costs for more profits compared with those created by the companies working individually. And as the profits are created by all the partners in the supply chain and there are no definite standards to define the contribution of each partner, it is difficult to allocate the profits perfectly.

In this paper, it will apply the Shapley Value algorith $m$ proposed by L. S. Shapley to solve the profit allocation among the cooperative enterprises in the supply chain. This kind of profit allocation is not to average out the profits or to allocate according to the ratio of the investment cost, but to allocate the profits according to the importance of the cooperative partners in the profit production in the supply chain. And researchers should modify the algorithm based on the efforts, risks and capital appreciation of the enterprises.

\section{THE INTRODUCTION AND APPLICATION OF THE SHAPLEY VALUE}

\section{A. The Introduction to the Shapley Value}

The Shapley Value is a mathematical algorithm proposed by L. S. Shapley for the cooperative n-person game. Suppose there are $n$ persons participating in one business activity, the cooperation of them would help them acquire profits and their cooperation would get the most profits if their business activities are non-antagonistic and the Shapley Value is the way to allocate the most profits and is defined as the follows:

Suppose the set $I=\{1,2, \ldots, n\}$, and any subset $\mathrm{S}$ of $\mathrm{I}$ ( $\mathrm{S}$ stands for the random combination of $\mathrm{n}$ persons) matches a real valued function $\mathrm{v}(\mathrm{s})$ which meets the following requirements:

$$
v(\varnothing)=0
$$

$$
v\left(s_{1} \cup s_{2}\right) \geq v\left(s_{1}\right)+v\left(s_{2}\right), s_{1} \bigcap s_{2}=\varnothing,\left(s_{1} \subseteq I, s_{2} \subseteq I\right)
$$

Here $[\mathrm{I}, \mathrm{v}]$ is the cooperative game of $\mathrm{n}$ persons, and $\mathrm{v}$ is the characteristic function. $\mathrm{Xi}$ represents the profits allocated to $\mathrm{i}$ of $\mathrm{I}$ from the most profits $\mathrm{v}(\mathrm{I})$. under the cooperation, the allocation of the cooperative game is represented by $x=\left(x_{1}, x_{2}, \ldots, x_{n}\right)$. And the successful cooperation should meet the requirement $\sum_{i=1}^{n} x_{i}=v(I), x_{i} \geq v(i), i=1,2, \ldots, n$

$\varphi_{i}(v)$ stands for the allocation of $\mathrm{i}$ of $\mathrm{I}$, and the Shapley Value for the allocation of each member of $\mathrm{I}$ is $\phi(v)=\left(\varphi_{1}(v), \varphi_{2}(v), \ldots, \varphi_{n}(v),\right)$, and

$$
\varphi_{i}(v)=\sum_{s \in S_{i}} w(|s|)[v(s)-v(s \backslash i)], i=1,2, \ldots, n
$$

$$
w(|s|)=\frac{(n-|s|) !(|s|-1) !}{n !}
$$


$S_{i}$ is any subset of the set I, and $|S|$ is the number of elements of the subset s, while $w(|s|)$ is the weighting factor. $v(s)$ is the benefit of the subset of s, and $v(s \backslash i)$ is the benefit of the subset of $s$ with the profit of the company i removed.

\section{B. The Application the Shapley Value in the Profit Allocation of Cooperative Enterprises}

In the cooperation of the enterprises in the supply chain each economic entity optimize its core competence to maximize its profits; then, the economic activities of the cooperative enterprises can be regarded as the cooperation of several persons, and the profit allocation of these enterprises as the profit allocation of cooperative n-person game and is solved with the Shapley Value. In the model of the Shapley Value, $N$ is the set of $n$ enterprises, and $S$ is the subset of $N, s_{i}$ is all the subsets for the enterprise(s) $i$ of $N$, and $v(s)$ is the profits created by the subset $S . v(s \backslash i)$ is the profits of the subset $S$ with the profit of the company $i$ removed. And the difference between $v(s)$ and $v(s \backslash i)$ would reveal to what degree the company $i$ contributes to the profits of the subset $S$. here researchers take an example to illustrate this. Suppose there are three companies that respectively are raw material supplier, manufacturer, and retailer. And their acquired profits in cooperation and non-cooperation each year can be displayed in the following table.

TABLE I.

THE PROFITS OF THE COOPERATIVE ENTERPRISES IN THE SUPPLY CHAIN OF AGRICULTURAL PRODUCTS

\begin{tabular}{|l|c|}
\hline \multicolumn{1}{|c|}{ The Combination of Enterprises } & Profits (yuan) \\
\hline Manufacturer $(\mathrm{m})$ & 300,000 \\
\hline Retailer (r) & 200,000 \\
\hline Raw material supplier ( $)$ & 100,000 \\
\hline Manufacturer + retailer ( $\mathrm{m}+\mathrm{r})$ & 600,000 \\
\hline Manufacturer+ Raw material supplier (m+s) & 700,000 \\
\hline Retailer + Raw material supplier ( $\mathrm{r}+\mathrm{s})$ & 500,000 \\
\hline Manufacturer+ + Retailer + Raw material supplier (m+r+s ) & 1200,000 \\
\hline
\end{tabular}

From the table above, researchers can see that the profits in cooperation are more than that in noncooperation, and the combination of three enterprises is better than that of two. According to the Shapley Value, the profit allocation of the three should respectively be:

$$
\begin{aligned}
& \varphi_{m}=\frac{300}{3}+\frac{(600-200)+(700-100)}{6}+\frac{(1200-500)}{3}=500 \\
& \varphi_{r}=\frac{200}{3}+\frac{(600-300)+(500-100)}{6}+\frac{(1200-700)}{3}=350 \\
& \varphi_{s}=\frac{100}{3}+\frac{(700-300)+(500-200)}{6}+\frac{(1200-600)}{3}=350
\end{aligned}
$$

The results reveal that the allocation is reasonable both for the combination of enterprises as it realizes the profit maximization of the whole supply chain and for the individual as it makes the profit of each enterprise is more than that in non-cooperation. Meanwhile, the results show clearly that the allocation according to the Shapely Value is not an average or the allocation based on the ratio of investment cost, but a way to illustrate the importance of each individual in the cooperation, which can enhance the initiative of cooperative enterprises and improve the stability of the supply chain.

\section{The Modification to the Shapley VAlue}

\section{A. Limitations of the Shapley Value}

From the description above, the allocation is not perfect. For example, the enterprises in a supply chain can choose how many efforts they put in, and the profit of the whole supply chain is not only created by one individual but also by all the other me mbers. Therefore, this kind of allocation would result in laziness in some enterprise.

The allocation does not take into account the risks faced by enterprises in a supply chain, for it only considers the risks on average. And the risks are taken differently by enterprises. For those who face greater risks, their profits should be allocated both based on the Shapley Value and the risks they faced. Only by this can the cooperative enterprises be encouraged to take risks which enable the whole supply chain to work efficiently.

Besides, the capital appreciation of enterprises is also a key factor for the profit allocation. As researchers know, for a company whose capital appreciation is higher, it should take a bigger ratio in the allocation according to its contribution. But the Shapley Value only concerns how the profits should be allocated, and ignores how these profits are created. Then it only allocates the profits according to the contribution on average. Therefore, this kind of allocation is not fair, and harms the initiative of the enterprises which contribute more in the supply chain in a long term and makes the whole supply chain unstable.

\section{B. The Modifications to the Shapley Value}

In this paper, the Shapley Value takes the above factors on average, that is to say, each enterprise in the supply chain undertakes all the factors on average, which researchers take it as $\bar{G}=\frac{1}{n}$. Obviously, this only exists ideally, not practically. Then, researchers should modify the value to meet the practical. From the above, the total profit in cooperation is $v(s)$ in the supply chain. And based on the efforts, risks and capital appreciation of each enterprise, the profit allocation of each is $v(i)$. Suppose each enterprise gets profits $v(i)^{\prime}$ in practical. The practical factor of the cooperative partners is $G_{i}$, and the difference is $\Delta G_{i}=G_{i}-\frac{1}{n}$, and so $\sum_{i=1}^{n} G_{i}=1, \quad$ and 
$\sum_{i=1}^{n} \Delta G_{i}=0 . \Delta G_{i}$ represents the difference between ideally and practically, which is the modifying factor. Then the modified practical profit should be $\Delta v(i)=v(s) \times \Delta G_{i}$, and then the practical allocated profit should be $\Delta v(i)^{\prime}=v(i)+\Delta v(i)$.

The specific modifications are as follows:

When $\Delta G_{i} \geq 0$, which means that the efforts, risks and capital appreciation of a cooperative partner is more in the practical than in the ideal, then, this partner should be allocated more profits and the added profits should be $\Delta v(i)=v(s) \times \Delta G_{i}$, and then the profits it should be allocated practically is $\Delta v(i)^{\prime}=v(i)+\Delta v(i)$.

When $\Delta G_{i} \leq 0$, which means that the efforts, risks and capital appreciation of a cooperative partner is less in the practical than in the ideal, then, allocated profits of this partner should remove the corresponding part $\Delta v(i)=v(s) \times\left|\Delta G_{i}\right|$, and then get it real profits $\Delta v(i)^{\prime}=v(i)-\Delta v(i)$.

\section{Practical Examples to Illustrate the Modified Shapley Value}

The modifying factor is to be analyzed by analytic hierarchy process to establish the allocation system, and then give the assignment to the influencing factors to get the value of the modifying factor. Here researchers have got the value of the modifying factor by assumptions: $G_{m}=0.4, G_{r}=0.3$, and $G_{s}=0.3$, then researchers can get $\Delta G_{m}=\frac{2}{30}, \Delta G_{r}=-\frac{1}{30}, \Delta G_{s}=-\frac{1}{30}$. Therefore, $\Delta v(m)^{\prime}=580, \Delta v(r)^{\prime}=310, \quad$ and $\Delta v(s)^{\prime}=310$. Regarding efforts, risks and capital appreciation, this kind of allocation is more close to the practical conditions, which would be better accepted by the cooperative partners and render the stability of the cooperation in the supply chain.

Then the paper compares two kinds of allocation before and after the modifications of The Shapley Value. It will illustrate with two examples.

TABLE II.

THE COMPARISON OF THE PROFIT ALLOCATION OF AgRICULTURAL ENTERPRISES IN SiCHUAN (1)

\begin{tabular}{|c|c|c|c|c|c|c|c|}
\hline Allocation & $\mathbf{m}$ & $\mathbf{r}$ & $\mathbf{s}$ & $\mathbf{m} \cup \mathbf{r}$ & $\mathbf{m} \cup \mathbf{s}$ & $\mathbf{r} \cup \mathbf{s}$ & I \\
\hline Shapley value & 500 & 350 & 350 & meet & meet & meet & meet \\
\hline $\begin{array}{c}\text { Modified Shapley } \\
\text { value }\end{array}$ & 580 & 310 & 310 & meet & meet & meet & meet \\
\hline
\end{tabular}

From Table 2, the two kinds of allocation meet the characteristic function, and then are accepted by all the enterprises. Researchers can see that the modified Shapley Value is more close to the practical. If researchers adopt this, the cooperation among enterprises in the supply chain would work well. Then it is practical to modify the Shapely Value. And maybe the modified Shapley Value would not meet the characteristic function and the

allocation seems unstable, but it still works, based on the negotiations and agreements. For example, if researchers get $G_{m}=0.35, G_{r}=0.5, G_{s}=0.15$, and then the results for the allocation are $\Delta v(m)^{\prime}=520$, $\Delta v(r)^{\prime}=550, \Delta v(s)^{\prime}=130$, illustrated in the following table.

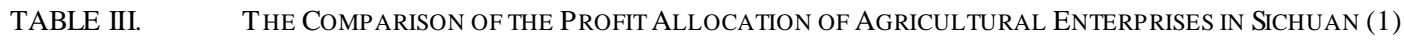

\begin{tabular}{|c|c|c|c|c|c|c|c|}
\hline Allocation & $\mathbf{m}$ & $\mathbf{r}$ & $\mathbf{s}$ & $\mathbf{m} \cup \mathbf{r}$ & $\mathbf{m} \cup \mathbf{s}$ & $\mathbf{r} \cup \mathbf{s}$ & I \\
\hline Shapley value & 500 & 350 & 350 & meet & meet & meet & meet \\
\hline $\begin{array}{c}\text { Modified Shapley } \\
\text { value }\end{array}$ & 520 & 550 & 130 & meet & Not meet & meet & meet \\
\hline
\end{tabular}

From the above table, the stability of the Shapley Value does not maintain. And if there are no negotiations and agreements, the raw material supplier would not accept this kind of allocation. But although they get less profit, they still can get more in cooperation than individually. Thus, the raw material supplier would also accept it. To be sure, researchers cannot ignore that the raw material supplier would cooperate with the manufacturer, and it also promise to give more than 520 to the manufacturer. If it does, then the stability of the supply chain is at risk. However, the manufacturer in general has obtained more than the allocated profits based on the Shapley Value. Therefore, the manufacturer would not cooperate with the raw material suppliers.

\section{CONCLUSIONS}

The reasonable profit allocation is a cruel presupposition for a supply chain to work. It is discussed that the Shapely Value only allocates the profits according to the contribution on average. If it is not modified, then the whole supply chain would be broken sooner or later. In this paper, it is suggested that the Shapley Value should be modified based on the efforts, risks and capital appreciation of each enterprise to calculate the deserved profits allocated to the cooperative enterprises in the supply chain. This modified one is feasible and reasonable, easy to be accepted by the cooperative enterprises.

\section{REFERENCES}

[1] Martin Christopher. Logistics and Supply Chain Management[M]. Beijing: Beijing Publishing House, 2001. 
[2] Shihua Ma, Yong Lin. Supply Chain Management[M]. Beijing: Higher Education Press, 2003.

[3] Lixuesong. Supply chain management[M]. Tsinghua University press, 2010.

[4] Yongkai Wang. Study on the Liner Shipping Strategic Alliance with Cooperative Game Theory[D]. Dalian: Dalian Maritime University, 2005.

[5] Yugang Wan. Game and Trust Analysis on Enterprises' Relationship of Supply Chain [D]. Nanjing University of Technology, 2005.

[6] Shihua Ma, Peng Wang. The Profit Allocation of the Cooperative Partners in Supply Chain based on the Shapley Value [J]. Gongye Gongcheng Yu Guanli, 2006 (4): 43-45.

[7] Baimapeng. Design and optimization of supply chain financial service system[D]. Tianjin University, 2008.

[8] Yang Weimin. Research on Structure Optimization of China's vegetable supply chain[D]. Chinese Academy of Agricultural Sciences, 2006.

[9] Qiu Zhongquan. Research on the optimization of the closed supply chain logistics network of green agricultural products[D]. Southwest Jiao Tong University, 2010.

[10] Zhong Zhehui. Supply chain information sharing model and its optimization[D]. Southwest Jiao Tong University, 2010.

[11] Geng Xurong. Optimization of agricultural super docking in China from the perspective of supply chain [D]. Shanxi University of Finance and Economics, 2013

[12] Zhang Xuan. Study on the optimization of agricultural products supply chain model in Fuzhou [D]. Fujian Agriculture And Forestry University, 2014.

[13] Ceng Deqiang. Optimization simulation of agricultural products supply chain logistics system [D]. Inner Mongolia University of Science and Technology, 2013.

[14] Lan Tingting. Research on the optimization strategy of vegetable supply chain management model [D]. Changchun University of Technology, 2014.
[15] Xu Jing. Empirical research on the construction and optimization of the supply chain model of the safe vegetable in Wenzhou [D]. Zhejiang University, 2006.

[16] Chen Shaohui Research on the optimization of the time and space operation of fresh agricultural products (FAP) supply chain [D]. Tianjin University, 2008.

[17] He Jing Research on the integrated optimization of grain supply chain in Beijing City [D]. Beijing Jiaotong University, 2011.

[18] Dong Yugui. Optimization of distribution network in the supply chain of agricultural products [D]. Dalian Maritime University, 2006.

[19] Hou Yunhe. Study on the coordination and optimization of crop seed supply chain [D]. Henan Agricultural University, 2011.

[20] Du Jingna. Study on the optimization of the vegetable supply chain model in Harbin City [D]. Northeast Agricult ural University, 2010.

[21] Liu Yijie. Research on the cost optimization of green supply chain based on IGA [D]. Hebei University of Engineering, 2011.

[22] Shen Xianghao. The optimization of key link in supply chain management of agricultural products distribution center [D]. Henan University of Science and Technology, 2011.

[23] Yang Xiaoxi. Research on Supply Chain Optimization Based on information ecology theory [D]. Huazhong Normal University, 2009.

[24] Sheng Jie. Study on supply chain optimization of C food company [D]. Beijing Jiaotong University, 2007.

[25] Xu Mingfang. Research on dynamic optimization model of green supply chain [D]. Chongqing University, 2007.

[26] Liang Junwei Application of information technology in supply chain management process optimization [D]. Guangdong University of Technology, 2006.

[27] Ma Fujing. Research on some optimization problems in the location and distribution of agricultural supply chain [D]. Shandong Normal University, 2006.

[28] Guo Renyong. Two supply chain optimization model and optimization algorithm [D]. Inner Mongolia University, 2006. 